Article

\title{
Immune Cell Production Is Targeted by Parasitoid Wasp Virulence in a Drosophila-Parasitoid Wasp Interaction
}

\author{
Jordann E. Trainor, Pooja KR and Nathan T. Mortimer*D \\ School of Biological Sciences, Illinois State University, Normal, IL 61790, USA; \\ jordanntrainor94@gmail.com (J.E.T.); pkadaba@ilstu.edu (P.K.) \\ * Correspondence: ntmorti@ilstu.edu
}

Citation: Trainor, J.E.; KR, P.

Mortimer, N.T. Immune Cell

Production Is Targeted by Parasitoid Wasp Virulence in a Drosophila-

Parasitoid Wasp Interaction. Pathogens 2021, 10, 49. https://doi.org/10.3390/ pathogens10010049

Received: 5 December 2020

Accepted: 5 January 2021

Published: 8 January 2021

Publisher's Note: MDPI stays neutral with regard to jurisdictional clai$\mathrm{ms}$ in published maps and institutional affiliations.

Copyright: (C) 2021 by the authors. Licensee MDPI, Basel, Switzerland. This article is an open access article distributed under the terms and conditions of the Creative Commons Attribution (CC BY) license (https:// creativecommons.org/licenses/by/ $4.0 /)$.

\begin{abstract}
The interactions between Drosophila melanogaster and the parasitoid wasps that infect Drosophila species provide an important model for understanding host-parasite relationships. Following parasitoid infection, D. melanogaster larvae mount a response in which immune cells (hemocytes) form a capsule around the wasp egg, which then melanizes, leading to death of the parasitoid. Previous studies have found that host hemocyte load; the number of hemocytes available for the encapsulation response; and the production of lamellocytes, an infection induced hemocyte type, are major determinants of host resistance. Parasitoids have evolved various virulence mechanisms to overcome the immune response of the D. melanogaster host, including both active immune suppression by venom proteins and passive immune evasive mechanisms. We identified a previously undescribed parasitoid species, Asobara sp. AsDen, which utilizes an active virulence mechanism to infect D. melanogaster hosts. Asobara sp. AsDen infection inhibits host hemocyte expression of $m s n$, a member of the JNK signaling pathway, which plays a role in lamellocyte production. Asobara sp. AsDen infection restricts the production of lamellocytes as assayed by hemocyte cell morphology and altered msn expression. Our findings suggest that Asobara sp. AsDen infection alters host signaling to suppress immunity.
\end{abstract}

Keywords: parasitoid wasp; virulence strategy; venom; immune cell; Drosophila

\section{Introduction}

Parasitoid wasps that infect Drosophila are a valuable model for understanding parasite behavior and have provided important ecological and molecular insights into host-parasite interactions [1-3]. In this system, parasitoids infect larval Drosophila, and following infection, Drosophila mount a cellular encapsulation response to overcome the invader [4]. This encapsulation response is highly conserved among arthropods [5-9], and encapsulation ability is an important determinant of pathogen resistance in insect vectors of human disease [10-12]. The encapsulation response in Drosophila melanogaster is mediated by hemocytes (immune cells), including circulating macrophage-like cells known as plasmatocytes, as well as lamellocytes, a highly specialized infection-induced immune cell subtype [13]. Plasmatocytes are physiologically activated by parasitoid wasp infection and, following activation, they migrate and adhere to the surface of the parasitoid egg [14,15]. Immune stimulation also triggers the production of lamellocytes [16,17], which adhere to the plasmatocyte cell layer and form a melanized capsule around the egg, killing the developing parasitoid $[15,18]$. There are multiple routes for lamellocyte production, including the transdifferentiation of plasmatocytes in circulation or within sessile populations, as well as differentiation directly from prohemocyte precursors in the lymph gland, the main hematopoietic organ in Drosophila [19-21].

It has been proposed that the main determinant of Drosophila immune resistance to parasitoid infection is host hemocyte load [22]. In this context, hemocyte load refers both to the number and activity of hemocytes found in circulation and the potential for 
the production of additional hemocytes following infection. Studies have found that an increased number of hemocytes confers resistance to parasitoid infection in D. melanogaster and other Drosophila species [23-27], and that the production and function of lamellocytes is critical for a successful encapsulation response [18,22,27].

Drosophila-infecting parasitoid wasps have evolved multiple mechanisms that allow them to evade or overcome the host immune response, the most prevalent of which is the transfer of venom virulence proteins into the host during infection. Because of the importance of hemocyte number for resistance, many of these parasitoid virulence mechanisms target host hemocytes. This includes venom virulence proteins that act on host hemocytes in a variety of ways including inducing hemocyte lysis [28], promoting death of hemocyte precursor cells $[29,30]$, and inhibition of hemocyte function leading to immunodeficiency $[14,18,31-34]$. Many of these venom proteins specifically target lamellocytes $[17,18,28,34,35]$, reinforcing the vital role that this hemocyte subtype plays in the encapsulation response. The outcome of these venom activities is to suppress host hemocyte load either by reducing the number or function of these immune cells.

Along with these active immune suppression mechanisms, parasitoids can also use passive immune evasive mechanisms to escape encapsulation [36,37]. Several passive mechanisms have been proposed including the binding of parasitoid eggs to host tissues as a form of camouflage from the immune response [14,36,38]; an increase in parasitoid egg size following infection [39,40]; and superparasitism, where a single host is multiply infected by conspecific parasitoids and has been suggested to increase parasitoid infection success [40-43].

In the present study, we describe an uncharacterized parasitoid species of the genus Asobara (Asobara sp. AsDen) to gain further insight into Drosophila-parasitoid interactions. We found that following infection, the host immune response is induced, but that host lamellocyte development is impaired, allowing the parasitoid to overcome the host immune defense. Asobara sp. AsDen is related to several well-studied Asobara species including Asobara tabida and Asobara citri, and thus our characterization of Asobara sp. AsDen can enable additional comparative studies with these species. The conservation of the encapsulation response in human disease vectors and the use of parasitoid wasps as biological control agents makes understanding parasitoid virulence strategies an important research goal.

\section{Results}

\subsection{AsDen Is a Strain of an Undescribed Asobara Species}

Female braconid wasps were caught in Denver, CO, USA in 2014 and allowed to infect the Ost $\Delta^{E Y 02442}$ encapsulation-deficient D. melanogaster strain [18]. These infections resulted in an all-female parthenogenetic strain, which was reared in the lab for three years prior to beginning experimentation. We sequenced the cytochrome oxidase I (COI) gene from this wasp strain and compared the sequence to COI sequences from known braconid species. Our sequence analysis suggests that the strain is a previously undescribed species of the genus Asobara. We refer to this wasp species using the name Asobara sp. AsDen or by the strain name AsDen to indicate the genus and location of collection.

Our basic local alignment search tool (BLAST) analysis of Asobara sp. AsDen revealed that the most closely related species are additional uncharacterized species of Asobara identified in recent efforts to catalog arthropod biodiversity (Table 1) [44-46]. In order to further characterize the evolutionary relationships between Asobara sp. AsDen and these other species, we performed phylogenetic analysis using COI sequences. We found that Asobara sp. AsDen forms a supported clade with the species Asobara sp. ABZ3773 and Asobara sp. ABX5347 [46] (Figure 1A). Interestingly these species are also found in North America (Table S1), further suggesting a recent evolutionary relationship. Additional phylogenetic analysis with previously studied species of Asobara suggests that the species group including Asobara sp. AsDen, Asobara sp. ABZ3773, and Asobara sp. ABX5347 is most closely related to Asobara triangulata, a species known from a single sample collected in Yunnan, China [47]; Asobara mesocauda, a species collected in South Korea and China [47]; 
and the well-studied species Asobara rufescens and Asobara tabida, which have both been found in Asia, Europe, and North America [46-48] (Figure 1B and Table S2).

Table 1. Basic local alignment search tool (BLAST) results comparing the AsDen COI DNA sequence against a custom database of 353 Asobara COI sequences. The species name, sequence accession number, score (bits), and identity (\%) for the top scoring hits by species are displayed.

\begin{tabular}{cccc}
\hline Species Designation & Accession Number & Score (Bits) & Identity (\%) \\
\hline Asobara sp. ABZ3773 & KR886087.1 & 974 & 94 \\
\hline Asobara sp. ABX5347 & JN293161.1 & 924 & 93 \\
\hline Asobara sp. ACF3746 & HQ929638.1 & 913 & 92 \\
\hline Asobara sp. ACE4721 & JN293665.1 & 907 & 92 \\
\hline Asobara sp. ACR5030 & MF936732.1 & 902 & 92 \\
\hline Asobara sp. ACF3747 & HQ930298.1 & 896 & 92 \\
\hline Asobara sp. AAE0947 & HQ106668.1 & 891 & 92 \\
\hline
\end{tabular}

\subsection{Asobara sp. AsDen Avoided Encapsulation by D. melanogaster Hosts}

AsDen wasps readily infected D. melanogaster larvae, with $98.8 \%$ of hosts infected after a 72-h exposure period ( $n=90$ larvae). We found that the D. melanogaster immune response successfully encapsulated only $36.6 \%$ of AsDen eggs ( $n=372$ eggs; an encapsulated egg is shown in Figure 2A). To survive infection, a host must encapsulate every infecting parasitoid egg, and we found that only $34.8 \%$ of infected D. melanogaster larvae were able to encapsulate all of the infecting AsDen eggs ( $n=89$ infected larvae), suggesting a high rate of successful parasitization of D. melanogaster hosts by AsDen. Interestingly, $77.5 \%$ of infected $D$. melanogaster larvae were infected more than once during the exposure period, for an average of $4.2 \mathrm{eggs} /$ infected host larva $(n=89$ infected larvae). We found a significant negative correlation between the number of eggs laid per larva and the proportion of eggs that are encapsulated (Figure 2B; Pearson's $r=-0.58, p<0.001$ ). Taken together, these data suggest that AsDen infection triggers the host immune response, but that it is able to successfully overcome host immunity in the majority of infections leading to successful parasitization of D. melanogaster hosts. Additionally, multiply infected host larvae are less likely to survive infection.

Similar to other Asobara species [39,40], we found that AsDen eggs continue to grow in size as they develop in D. melanogaster hosts. Eggs were dissected from infected D. melanogaster larvae at $48 \mathrm{~h}$ post-infection (hpi) and $72 \mathrm{hpi}$ and the length and width of each individual egg was determined. Unencapsulated eggs continue to increase in length (Figure $2 \mathrm{C} ; t=4.30, p<0.001$ ) and width (Figure 2D; $t=7.68, p<0.001$ ) between $48 \mathrm{hpi}$ and $72 \mathrm{hpi}$. To verify that encapsulation was arresting parasitoid development, we determined the length and width of individual encapsulated and melanized eggs at 48 hpi and 72 hpi to compare them with unencapsulated eggs. We found that the melanized eggs were significantly shorter (Figure 2C; $t=-8.28, p<0.001$ ), and narrower (Figure 2D; $t=-8.38$, $p<0.001$ ) than unencapsulated eggs at $72 \mathrm{hpi}$. Additionally, the increase in size that was seen in unencapsulated eggs was arrested in encapsulated eggs, with no significant size differences observed in encapsulated eggs dissected at 48 hpi and 72 hpi (Figure 2C,D; length: $t=1.24, p=0.60$; width: $t=-0.63, p=0.92)$. 
A

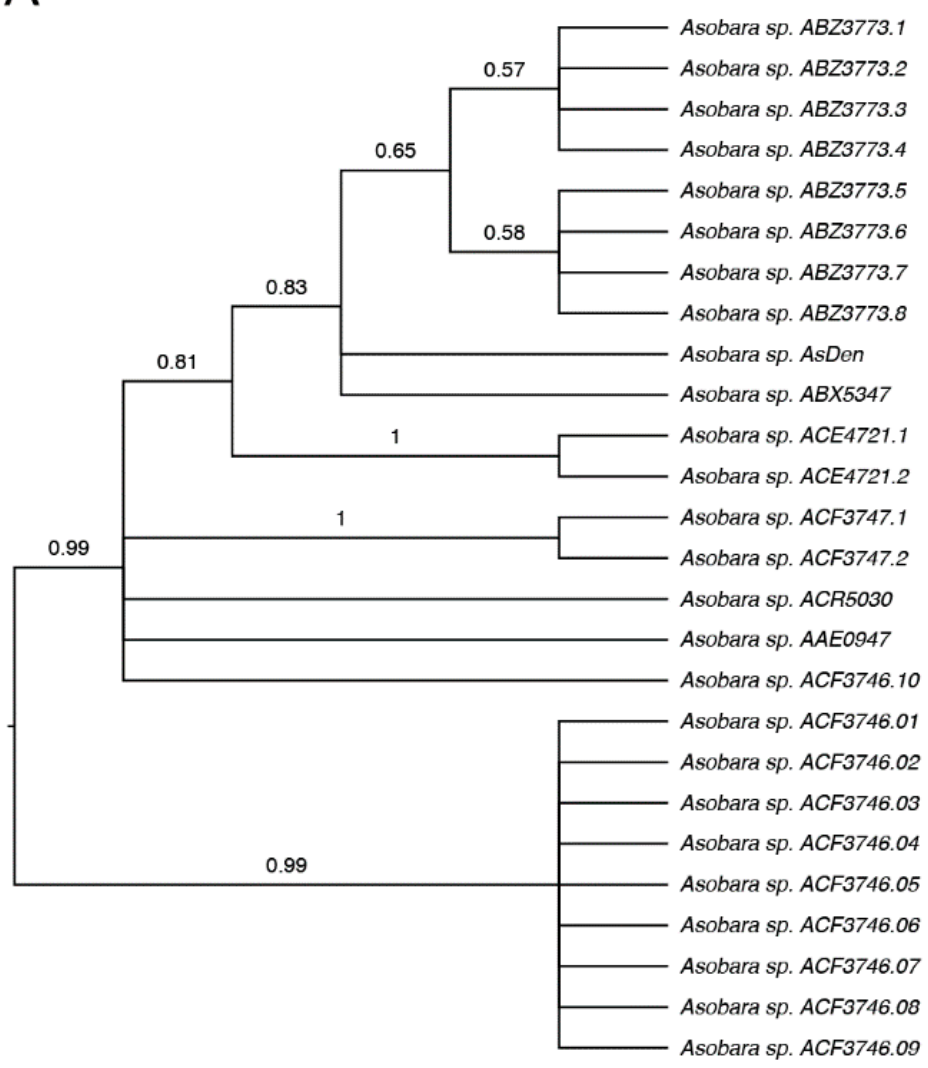

B

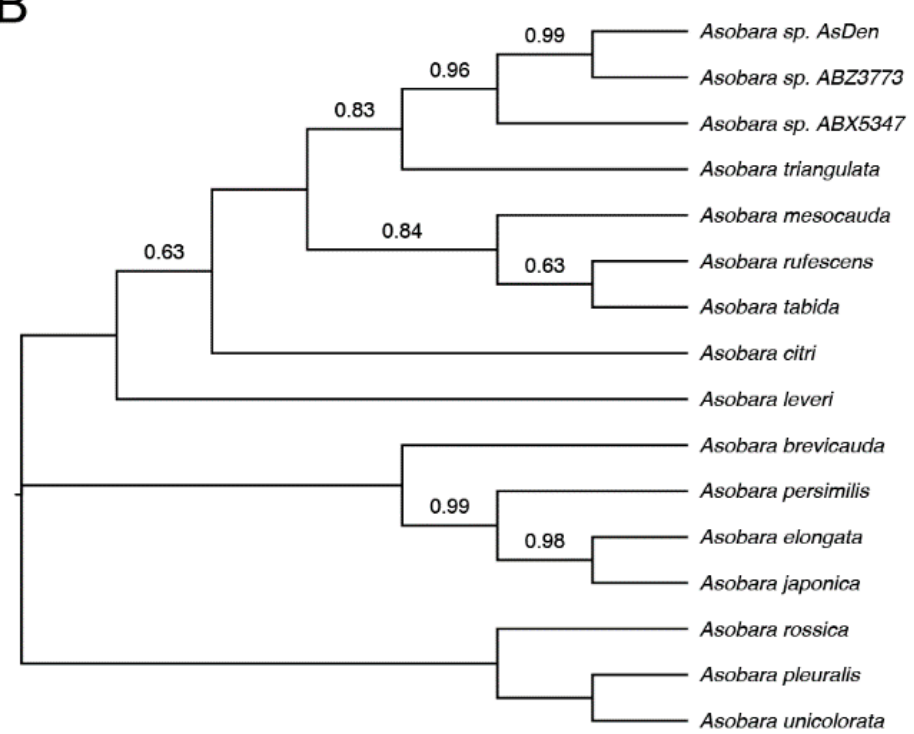

Figure 1. (A,B) Phylogenetic analysis of the cytochrome oxidase I (COI) gene in Asobara sp. AsDen with other species of the genus Asobara. The evolutionary history was inferred by using the maximum likelihood method as implemented in MEGA, and the tree with the highest log likelihood is shown. The proportion of trees from 1000 bootstrap replicates in which the associated taxa clustered together is displayed, and values below 0.5 are not shown. (A) Phylogeny of Asobara sp. AsDen with sequences from 25 individuals belonging to closely related undescribed Asobara species (see Table S1 for sequence information). Strains of the same species have a numerical suffix appended to the species name. (B) Phylogeny of Asobara sp. AsDen with sequences from well-studied species of Asobara (see Table S2 for sequence information). 
A

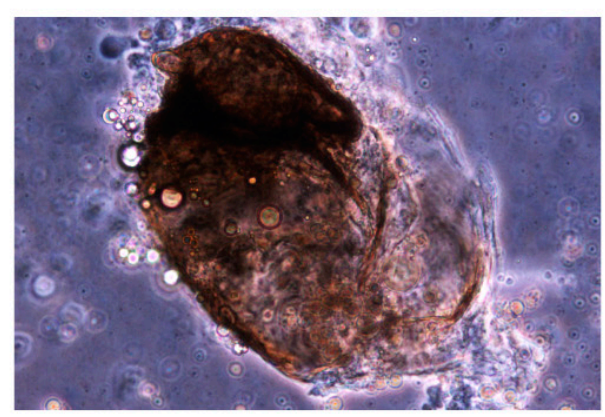

C

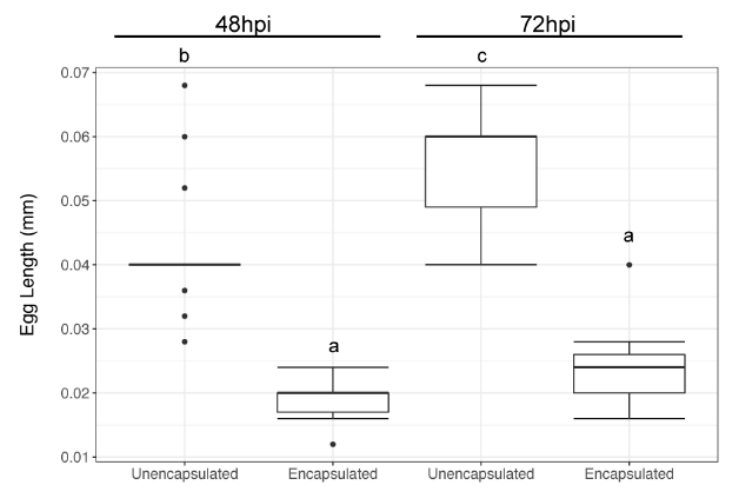

B

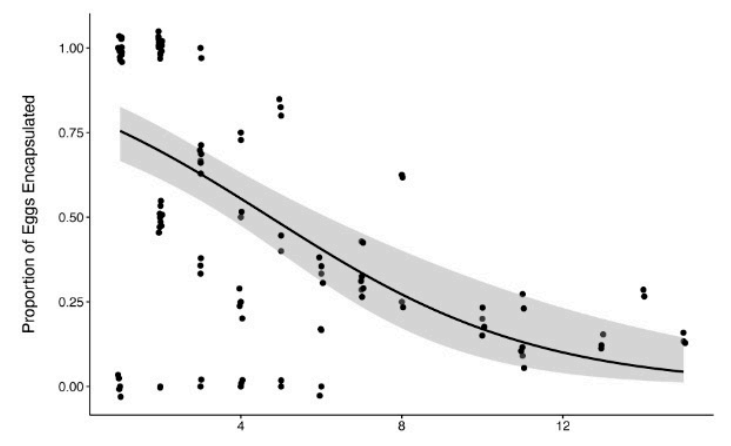

D

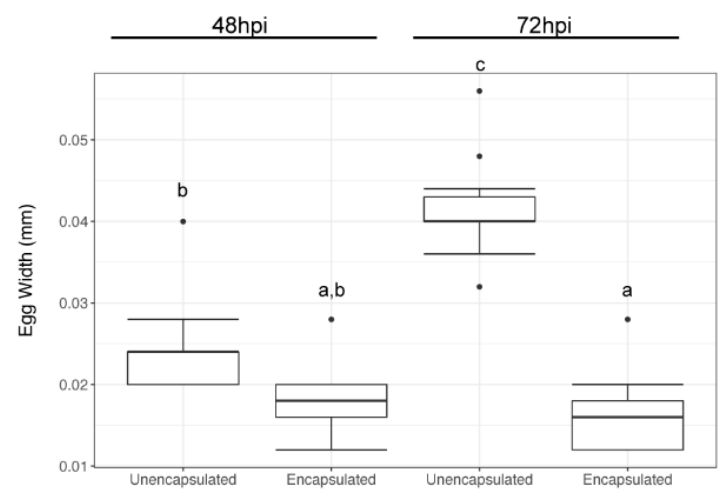

Figure 2. (A) Photomicrograph of an encapsulated AsDen egg dissected from a Drosophila melanogaster host. (B) Scatterplot showing the correlation between the number of infections and the proportion of AsDen eggs encapsulated in $w^{1118}$ hosts. Individual data points and the logistic regression line are shown. The 95\% confidence interval is shaded in grey and individual data points are jittered on both the $x$ - and $y$-axes for clarity. The length $(\mathbf{C})$ and width (D) of both unencapsulated and melanotically encapsulated AsDen eggs were determined at 48 and $72 \mathrm{~h}$ post-infection (hpi). Data are displayed as box plots, with calculated outlier data shown as individual points. Letters $(a-c)$ indicate significance groups within each experiment as determined by Tukey's honest significant difference (HSD).

\subsection{Host lamellocyte Production Is Impaired in Asobara sp. AsDen-Infected Larvae}

Many parasitoid species transfer venom virulence proteins to their host during infection to suppress hemocyte number or activity. Often, these virulence proteins target lamellocytes, a parasitoid infection-induced hemocyte subtype that is required for a successful encapsulation response [27-30]. Lamellocytes are larger and less circular than other hemocytes and can be distinguished from other hemocyte subtypes both by their unique morphology and by the specific expression of misshapen (msn) [49,50]. Lamellocytes are produced both by the direct differentiation of prohemocytes in the hematopoietic lymph gland and by the transdifferentiation of circulating or sessile plasmatocytes [16,19-21], and both routes result in $m s n$ expression [49].

To assay the production of lamellocytes in AsDen-infected larvae, we used a fluorescent cytometer to take high-throughput measurements of cell size, cell perimeter, cell circularity, and $m$ Cherry fluorescence intensity from hemocytes isolated from infected larvae of the $m s n$ - $m$ Cherry strain (Figure 3A). This strain expresses $m$ Cherry as a fluorescent reporter of $m s n$ expression [51]. Because lamellocyte production is induced by parasitoid infection, $m s n$ is not expressed in the hemocytes of naïve larvae, and thus we used infection with the parasitoid Leptopilina boulardi as a comparison for AsDen venom activity. L. boulardi infection does not inhibit expression of $m s n$ or lamellocyte development and thus provides a reliable control $[17,52,53]$. We found that following $L$. boulardi infection, $45.1 \pm 4.2 \%$ of circulating hemocytes expressed the $m s n$ - $m$ Cherry reporter ( $n=32,176$ hemocytes). In these L. boulardi-infected larvae, the $m s n$ - $m$ Cherry-positive cells were larger (cell size: $t=29.3$, 
$p<0.001$; cell perimeter: $t=29.4, p<0.001)$ and less circular $(t=21.8, p<0.001)$ than cells not expressing $m s n-m C h e r r y$, consistent with the described properties of lamellocytes [50]. We found that AsDen infection also triggered a cellular immune response and lamellocyte production as assayed by msn-mCherry expression in D. melanogaster hosts. However, only $21.4 \pm 1.8 \%$ of hemocytes in AsDen-infected msn-mCherry larvae were msn-positive ( $n=53,908$ hemocytes), a significantly lower proportion than observed in stage-matched L. boulardi-infected $m s n$ - $m$ Cherry larvae (Figure $3 \mathrm{~B} ; \mathrm{z}=7.33, p<0.001$ ). We further found that among the $m$ Cherry-positive hemocytes, cells from AsDen-infected larvae had significantly lower fluorescence intensity compared to cells from L. boulardi-infected larvae (Figure 3C; $\mathrm{z}=4.84, p<0.001)$.

A

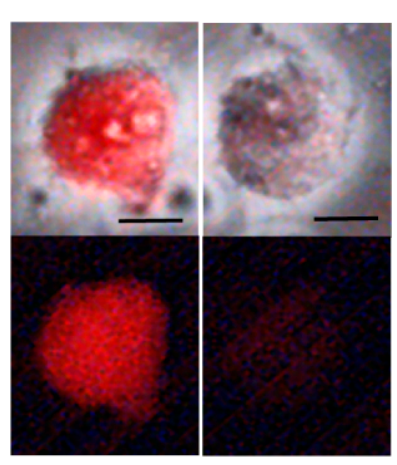

$\mathrm{B}$

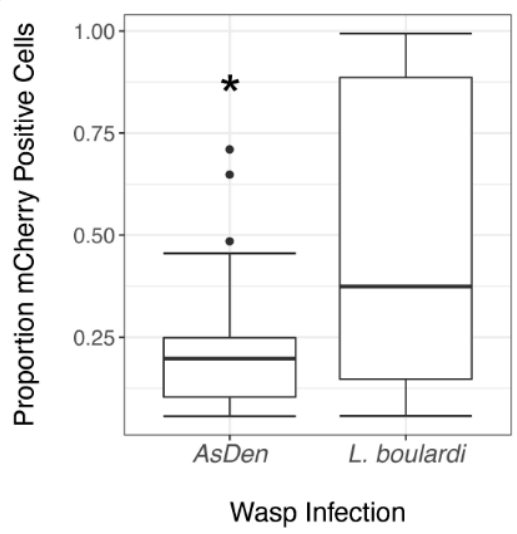

C

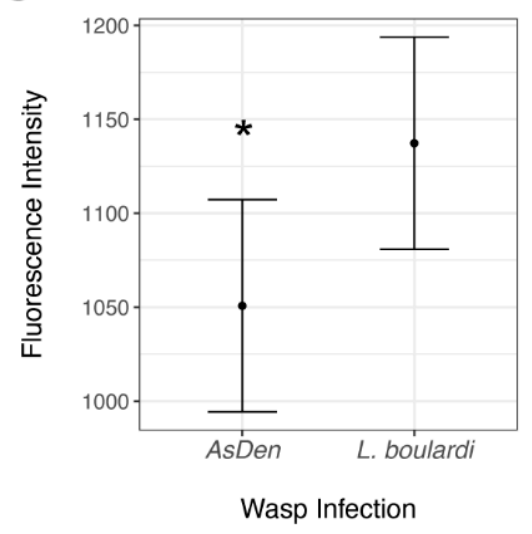

Figure 3. (A) Hemocytes dissected from parasitoid-infected msn-mCherry larvae. Top panels are merged bright-field and fluorescent images and bottom panels show fluorescence alone. Examples of $m s n$-expressing (left) and $m s n$-negative (right) hemocytes. Scale bars indicate $10 \mu \mathrm{m}$. (B) The proportion of hemocytes positive for $m$ Cherry isolated from AsDen and Leptopilina boulardi-infected msn-mCherry larvae at $72 \mathrm{hpi}$. Data are displayed as box plots, with calculated outlier data shown as individual points. (C) Calculated fluorescence intensity of $m$ Cherry-positive hemocytes isolated from AsDen and L. boulardi-infected larvae at $72 \mathrm{hpi}$. Data are displayed as the mean fit (point) of the effect of parasitoid species on fluorescence intensity \pm standard error. In (B) and (C), * indicates $p<0.05$ compared to L. boulardi-infected larvae.

These differences in msn expression may be predicted to result in differences in hemocyte morphology from L. boulardi and AsDen-infected larvae. To better compare cell morphology between infections, we used principal component analysis (PCA) to reduce the cell size, cell perimeter, and cell circularity measures from the cytometer data to a single dimension. The first principal component of this cell morphology PCA (PCM) had an eigenvalue of 2.35 and explained $78.4 \%$ of the variance among these data, suggesting that it accurately captured the data describing hemocyte morphology. We found that PCM values differed significantly between hemocytes from AsDen and L. boulardi infected larvae (Figure $4 \mathrm{~A} ; t=17.03, p<0.001$ ), implying that hemocyte morphology does vary by infection condition. While mature lamellocytes were produced by both L. boulardi- and AsDen-infected larvae (Figure 4B), most msn-expressing immune cells in AsDen-infected larvae tended to be smaller and rounder than mature lamellocytes (Figure 4C). This class of msn-expressing hemocytes showed an abnormal morphology in comparison with a mature lamellocyte and were not seen following L. boulardi infection.

To further characterize the hemocyte populations in AsDen- and L. boulardi-infected larvae, we performed a second PCA using the previously listed cell morphology features and $m$ Cherry fluorescence intensity data. We plotted the first two dimensions of this PCA (PC1 and PC2; Table 2), and we found that hemocytes from L. boulardi-infected larvae (red triangles in Figure 5A,B) largely clustered into two groups, distinguished by morphology and fluorescence intensity. Although hemocytes from AsDen-infected larvae fell into a similar pattern (black circles in Figure 5A,B), one of these groups was greatly 
reduced. The same pattern was replicated when only data from $m$ Cherry-positive cells were used for the PCA (Figure 5C,D). However, the PCA plots derived from $m$ Cherry-negative hemocyte properties were indistinguishable between AsDen- and L. boulardi-infected larvae (Figure 5E,F). These data supported the hypothesis that $m s n$-expressing hemocytes are differentially affected by the parasitoid infections. On the basis of the role of $m s n$ in lamellocyte production and the observed morphology differences, these data suggest that lamellocyte production is impaired following AsDen infection.

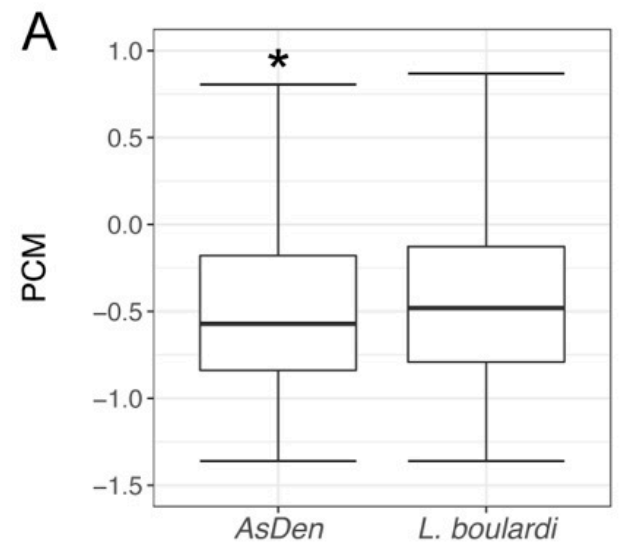

Wasp Infection
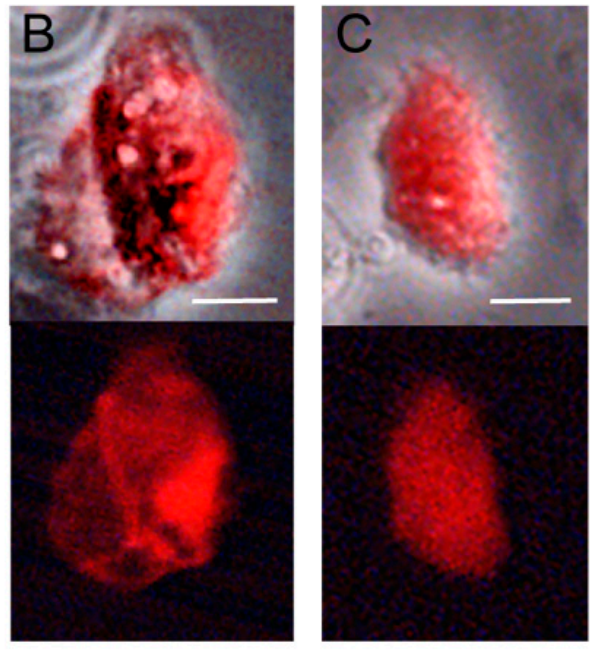

Figure 4. (A) Cell morphology principal component analysis (PCM) values calculated from hemocytes isolated from AsDen and L. boulardi-infected larvae at $72 \mathrm{hpi}$. Data are displayed as box plots. * indicates $p<0.05$ compared to L. boulardi-infected larvae. (B,C) Hemocytes dissected from AsDen-infected msn-mCherry larvae. Top panels are merged bright-field and fluorescent images and bottom panels show fluorescence alone. (B) Mature lamellocyte, and (C) morphologically abnormal msn-expressing immune cell from parasitoid-infected larvae. Scale bars indicate $10 \mu \mathrm{m}$.

Table 2. Eigenvalues and factor loading for the first two dimensions (PC1 and PC2) from PCA of cell morphology and fluorescence intensity of all hemocytes extracted from L. boulardi- and AsDen-infected msn-mCherry larvae, as shown in Figure 4A,B.

\begin{tabular}{ccc}
\hline Variable & PC1 & PC2 \\
\hline Eigenvalue & 1.624 & 0.867 \\
\hline Variance (\%) & 54.13 & 28.90 \\
\hline Factor loading & & \\
\hline Cell size & 0.647 & -0.262 \\
\hline Cell circularity & 0.636 & -0.332 \\
\hline Fluorescence intensity & 0.420 & 0.906 \\
\hline
\end{tabular}


A

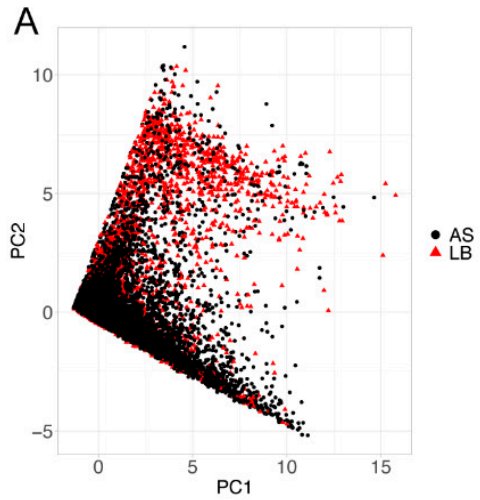

C

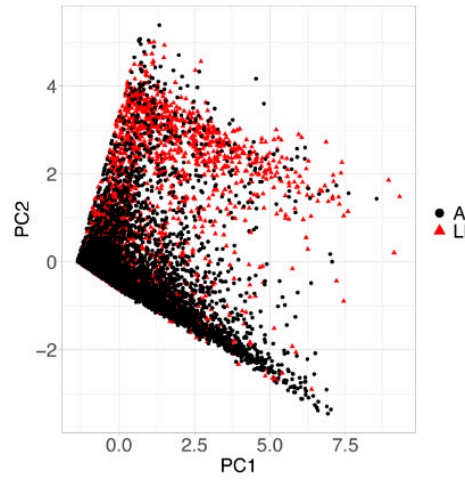

$\mathrm{E}$

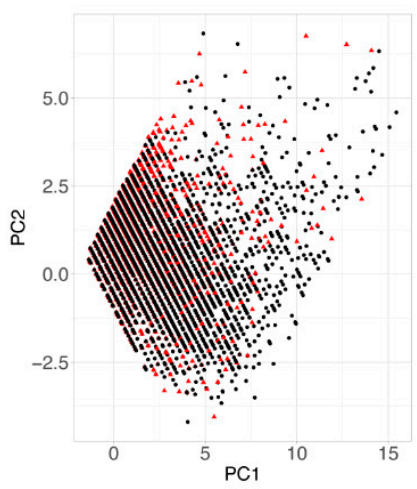

B

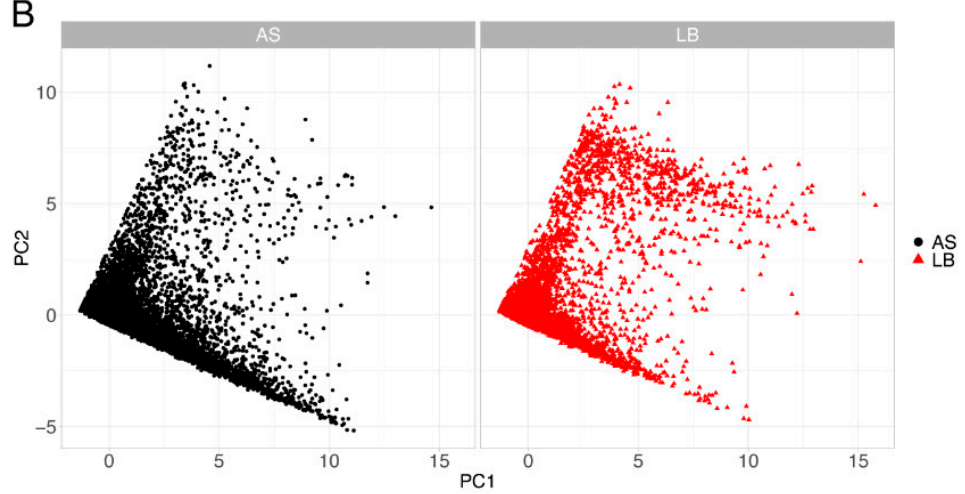

D

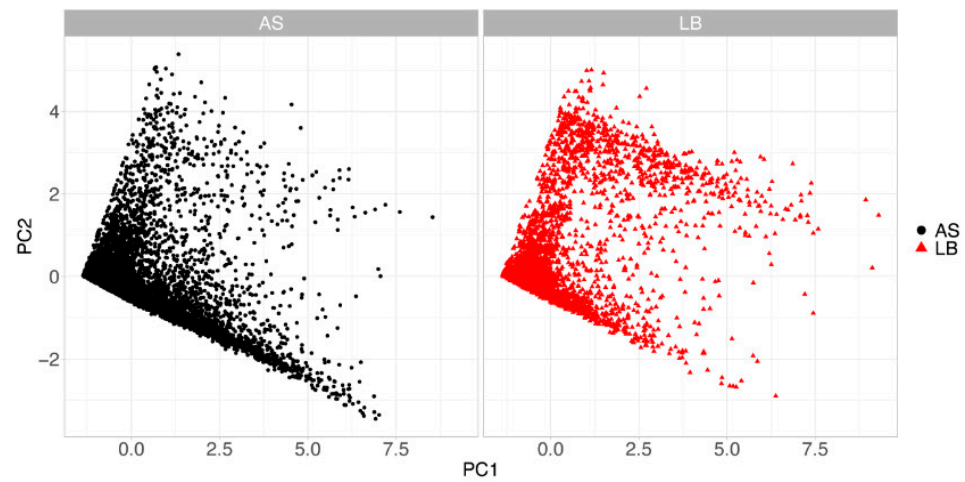

$\mathrm{F}$

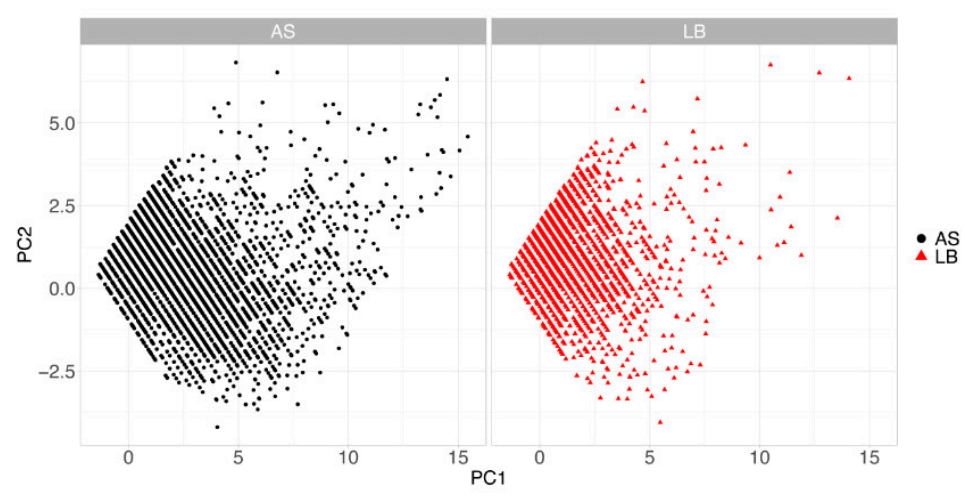

Figure 5. Plots of the first two principal components from a principal component analysis (PCA) of cell morphology and fluorescence intensity performed on (A,B) all hemocytes, (C,D) msn-mCherry-positive hemocytes, and (E,F) msn-mCherrynegative hemocytes. Hemocytes were extracted at $72 \mathrm{hpi}$ from $m s n$ - $m$ Cherry larvae infected by the indicated parasitoid. Hemocytes from AsDen-infected larvae (AS) are shown as black circles and as the left panel of faceted images (B,D,F), and hemocytes from $L$. boulardi-infected larvae (LB) are shown as red triangles and as the right panel of faceted images.

\section{Discussion}

Our findings suggest that a previously uncharacterized parasitoid species from the genus Asobara, represented here by the AsDen strain, can successfully parasitize D. melanogaster. Asobara sp. AsDen is evolutionarily related to other Drosophila-infecting parasitoids including $A$. tabida, although the host ranges of the more closely related, uncharacterized species found in North America are unknown. To characterize the effects of AsDen infection on host hemocyte load, and specifically hemocyte morphology and msn expression, we compared the properties of hemocytes from AsDen-infected hosts to hemocytes from L. boulardi-infected hosts. L. boulardi infection triggers $m s n$ expression and lamellocyte 
production, and L. boulardi venom has no known impact on these processes [17,38,52,53], suggesting that this infection can serve as a useful control for our analyses.

We found that AsDen infection triggers an immune response in hosts, but that it has a distinct effect on both hemocyte morphology and msn expression in host hemocytes when compared with L. boulardi infection. We interpret our findings to suggest that this effect of AsDen infection is a result of parasitoid venom activity, as has been shown in similar instances of Drosophila-infecting parasitoid wasp virulence [14,28,29,33-35]. However, it is possible that this effect is due to an unrecognized parasitoid virulence mechanism, and thus direct experimentation with AsDen venom will be necessary to strengthen this conclusion and explore the mechanism in future work.

In the encapsulation response, $m s n$ is expressed in lamellocytes following infection, and $m s n$ signaling activity is required for lamellocyte production [51,54]. The proportion of $m s n$-positive immune cells is lowered following AsDen infection, and msn expression levels are decreased in immune cells isolated from AsDen-infected larvae in comparison with L. boulardi-infected larvae (Figure 3). These findings suggest that AsDen infection inhibits host immune signaling, leading to the failure to properly promote lamellocyte specification or development. In agreement with this hypothesis, we observed that many msnexpressing cells from AsDen-infected larvae display an abnormal lamellocyte-like morphology (Figure 4B,C). Additionally, we found that while hemocytes from L. boulardi-infected hosts clustered into two populations on the basis of their morphology and msn expression levels, one of these populations was greatly reduced in AsDen-infected hosts (Figure 5A,B). Lamellocytes tend to be larger and more irregularly shaped than plasmatocytes [50]. An examination of the factor loading from our cell morphology and fluorescence intensity PCA results (Table 2) suggests that the reduced cell population in AsDen-infected larvae tended to be larger, less circular, and msn-positive (Figure 5), all of which are consistent with a specific deficit in lamellocyte production. The finding that this alteration in hemocyte characteristics was observed in $m s n$-positive cells (Figure 5C,D) but not $m s n$-negative cells (Figure 5E,F) further suggests that AsDen infection specifically targets $m s n$ and/or lamellocyte production.

The Msn protein functions in the JNK signal transduction pathway [55]. msn is transcriptionally regulated by JNK activity through a positive feedback loop, and thus the $m s n$ - $m$ Cherry reporter strain provides a readout of JNK pathway activity [51]. This suggests that the JNK signaling pathway may be inhibited in AsDen-infected larvae. We have yet to determine the molecular mechanism underlying JNK inhibition in AsDen infected larvae, but we propose it could act either directly through inhibiting one or more components of the JNK pathway or indirectly by blocking upstream pathway activation to inhibit lamellocyte production. The JNK pathway plays a conserved role in immunity in Drosophila and a wide range of species $[9,56,57]$. In D. melanogaster, genes in the JNK pathway are associated with resistance to parasitoids [58,59], and are required for lamellocyte production in response to infection [51]. To our knowledge, Drosophila parasitoids have not previously been suggested to inhibit JNK signaling; however, the JNK pathway is targeted by a wide range of other pathogens in a variety of hosts [60-62].

It is notable that AsDen-infected larvae do still produce $m s n$-positive hemocytes, suggesting that lamellocyte differentiation and JNK signaling are not completely abolished. Additionally, even though the morphological changes leading to lamellocyte production are impaired in AsDen-infected larvae, the cell morphology of msn-expressing hemocytes is different from non-msn-expressing hemocytes. These data suggest that AsDen infection may be inhibiting a specific aspect of lamellocyte transdifferentiation or maturation, consistent with the finding that $m s n$ expression coincides with early morphological changes in transdifferentiating hemocytes [49]. Recent studies have uncovered a broader range of Drosophila hemocyte subtypes than previously appreciated [63-66], and future investigation into this complexity may help to unravel the specific effects of AsDen venom on host hemocytes and lamellocyte production. 
These findings suggest that AsDen is exhibiting an active immune suppression virulence mechanism. In this proposed mechanism, lamellocyte production is triggered following infection but is suppressed by venom or another parasitoid factor, resulting in the morphologically abnormal lamellocyte-like hemocytes we observed. To our knowledge, these lamellocyte-like cells are not induced during the immune response to other parasitoids, suggesting that they result from the inhibition of lamellocyte development rather than as a typical component of the immune response. In contrast, we would predict that a passive evasion strategy would either fail to trigger any host immune response (including $m s n$ expression) or result in a reduced number of morphologically normal lamellocytes, rather than the abnormal cells seen following AsDen infection.

Along with restricted lamellocyte production or development, AsDen- infected hosts have a limited encapsulation response. Interestingly, we found a negative correlation between the number of times a host larva was infected and its encapsulation ability (Figure 2A). Multiple infections of a single host by conspecific parasitoids is known as superparasitism [67], and is commonly observed across many parasitoid species both in laboratory conditions and in nature. The negative effect of superparasitism on host resistance observed in our study may have been due to the additive effects of multiple envenomations on host lamellocyte production; perhaps additional "doses" of venom are able to more completely suppress lamellocyte production. However, we cannot rule out the possibility that superparasitism is acting through an alternative mechanism such as passive immune evasion [36,37]. Supernumerary infections by the parasitoids Pseudapanteles dignus and A. tabida have been shown to increase the likelihood of successful parasitization [40,42], suggesting that superparasitism itself may contribute to the ability of the parasitoid egg to escape from encapsulation. Parasitoids generally avoid superparasitism and most parasitoid species are able to perceive the presence of eggs from a conspecific female $[39,41,68]$. In our previous work, we found that using the identical experimental setup with other parasitoid species consistently yields average infection rates of 1-1.2 eggs per infected larva $[14,38]$. This is in contrast to the 4.2 eggs per infected larva observed for AsDen in this study. Many known instances of superparasitism are driven by external factors such viral infections [69-71], but this has not yet been determined in this case.

In Asobara sp. AsDen and many other parasitoid species, virulence appears to be largely driven by a single strategy, for example, the passive immune avoidance of $A$. tabida or the immune suppressive venoms of AsDen, Asobara citri, Asobara japonica, or various species of Figitid parasitoid wasps [30,32,36,72-74]. However, both L. boulardi and Ganaspis hookeri appear to use a combined strategy of venom-mediated immune suppression and passive avoidance $[14,37,38]$, suggesting that further study may uncover more complex virulence strategies across a range of parasitoids than previously appreciated. Further, while A. tabida is the most closely related of the well-studied parasitoid species to Asobara sp. AsDen, its venom has been shown to cause paralysis and inhibit host development with only limited immune-suppressive effects [36,75-79]. This is not entirely unexpected, as other closely related parasitoid species have distinct virulence strategies and venom composition $[37,38,80]$. It has also been demonstrated that different strains of a single parasitoid species can possess different virulence activities [81-83]. As AsDen is the only known strain of its species, we were unable to determine how conserved this activity may be with other strains, although this will hopefully be investigated as more strains of this species are identified.

Our findings support the idea that overcoming host hemocyte load is a critical determinant of parasitization success for parasitoid wasps of Drosophila. Since Drosophila are a valuable model for understanding the immune defenses of insect vectors of human disease and agricultural pests, these findings may provide insight into the interactions between insect vectors and invading pathogens and may have implications for the selection and use of parasitoid wasps in biological control applications. 


\section{Materials and Methods}

\subsection{Insect Strains}

Two females from an unknown braconid parasitoid wasp species were collected from a fruit trap in Denver, Colorado, USA, in 2014 and were maintained on the encapsulation deficient D. melanogaster mutant strain Ost $\Delta^{E Y 02442}$ (BDSC: 15565) [18] from the Bloomington Drosophila Stock Center. A sub-strain was established from a single parthenogenetic foundress and will be referred to as AsDen. The study also uses the parasitoid wasp Leptopilina boulardi (strain Lb17) [38], which is maintained in the laboratory on the Canton S D. melanogaster strain. The following additional D. melanogaster strains were used in this study: $w^{1118}$ (BDSC: 5905) from the Bloomington Drosophila Stock Center, and msn-mCherry [51], provided by Dr. Robert Schulz.

\subsection{Parasitoid Species Determination}

Genomic DNA was extracted from AsDen using standard methods. The COI gene was amplified using the "Folmer" primers [84] LCO1490 (primer sequence: GGTCAACAAATCATAAAGATATTGG) and HCO2198 (primer sequence: TAAACTTCAGGGTGACCAAAAAATCA), and sequenced at the UIUC Core Sequencing Facility (Urbana, IL). The resulting Sanger sequencing reads were aligned using 4Peaks software (A. Griekspoor and Tom Groothuis, nucleobytes.com). The Asobara sp. AsDen COI DNA sequence was submitted to GenBank (accession \# MT498809). The resulting DNA sequence was compared against all hymenopteran sequences using the basic local alignment search tool (BLAST) available through the National Center for Biotechnology Information (NCBI) [85]. For further sequence analysis, we constructed a custom BLAST database of all 353 Asobara COI sequences available from the NCBI (accessed April 11, 2020) using BLAST+ (version 2.5.0) [86]. This custom BLAST database is available upon request.

\subsection{Phylogenetics}

Phylogenetic analyses were conducted in MEGA X $[87,88]$ using COI DNA sequences. For the first analysis, AsDen was compared to the 25 most highly homologous Asobara sequences as determined by BLAST+ (Supplemental Table S1) [44-46]. For the second analysis, the species group including AsDen found in the first analysis was compared against 13 well-studied species of Asobara (Supplemental Table S2) [26,47,89,90]. For both analyses, the evolutionary history was inferred by using the maximum likelihood method and Kimura 2-parameter model with 1000 bootstrap replicates [91]. The initial tree for the heuristic search was obtained automatically by applying Neighbor-Join and BioNJ algorithms to a matrix of pairwise distances estimated using the maximum composite likelihood (MCL) approach in MEGA X, and then selecting the topology with superior log likelihood value. Branches corresponding to partitions reproduced in less than $50 \%$ of the bootstrap replicates were collapsed. All positions containing gaps and missing data were eliminated. The resulting phylogenetic trees were visualized using FigTree (version 1.4.3, http://tree.bio.ed.ac.uk/).

\subsection{Parasitoid Infection}

For infection with parasitoid wasps, 30 late second instar larvae from the $w^{1118}$ strain were placed on $35 \mathrm{~mm}$ Petri dishes filled with Drosophila medium together with 3 AsDen wasps at $25^{\circ} \mathrm{C}$. Larvae were dissected at 48 or $72 \mathrm{~h}$ post-infection (hpi), as noted. The infected larvae were then scored for the total number of parasitoid eggs and the numbers of encapsulated and non-encapsulated eggs. For size experiments, the length and width of each egg was determined using an E-series Reticle (Leica Microsystems). Egg length was measured from pole to pole and egg width was measured across the widest region perpendicular to the length axis. All experiments were performed in triplicate. 


\subsection{Expression of msn and Cell Morphology Analyses}

The $m s n$-mCherry D. melanogaster strain was used to assay expression of msn. This strain carries a transgenic construct containing the $m s n-F 9$ enhancer upstream of the $m$ Cherry red fluorescent protein [51]. Second instar $m s n-m C h e r r y$ larvae were exposed to either AsDen or L. boulardi for a 72-h period as described above, with 3 biological replicates for each infection condition. Host hemocytes were isolated $72 \mathrm{hpi}$ and added to a Tali Cellular Analysis Slide (Invitrogen). Hemocytes were allowed to adhere for $30 \mathrm{~min}$ and then cell number, size, perimeter, circularity, and red fluorescence intensity were measured using a Tali Image-Based Cytometer (Invitrogen). For each replicate, we imaged 20 fields of cells, with an average of 717.4 cells per field, and a range of 194 to 1455 cells for a total of 32,176 hemocytes from L. boulardi-infected larvae and 53,908 hemocytes from AsDeninfected larvae. Cytometer data were filtered to only include single cells using the Tali software count function and size-gating, prior to further analysis.

\subsection{Data Analysis}

All statistical analyses were performed in the R statistical computing environment [92] using the multcomp [93], lme4 [94], lmerTest [95], plyr [96], FactoMineR [97], factoextra [98], and ggplot2 [99] packages. Analysis of variance (ANOVA) was used to test the relationship between egg size and time or encapsulation status. Tukey's honest significant difference (HSD) test was used for multiple comparisons of egg size. Pearson's product-moment correlation was used to test for correlations between egg number and encapsulation status. Mixed linear models, with replicate as a random effect, were used to test for differences in $m s n$-mCherry fluorescence intensity and proportion of $m$ Cherry-positive cells between AsDen and L. boulardi infections. Welch two-sample $t$-tests were used to compare immune cell morphology data between AsDen and L. boulardi infections.

To characterize hemocyte populations, we used PCA on the red fluorescence intensity, cell size, cell perimeter, and cell circularity measures from the cytometer data. A circularity value of 1.0 is considered perfectly circular, and values either greater or less than 1.0 are increasingly less circular. To account for this, circularity values were $\log _{2}$ transformed and the absolute value of these transformed values were used for PCA. Other measures were used for PCA without transformation. This analysis was repeated separately on gated fluorescence data, generating distinct PCA scores for $m$ Cherry-positive hemocytes and $m$ Cherry-negative hemocytes.

Supplementary Materials: The following are available online at https:/ /www.mdpi.com/2076-0 817/10/1/49/s1: Table S1: Species names, accession numbers and collection location are given for samples used to build the phylogeny shown in Figure 1A. Multiple individuals of a species are listed as independent samples with accession numbers and a numerical suffix appended to the species name. Abbreviations: NP (National Park), SP (State Park). Table S2: Species and strain names, accession numbers and collection location are given for samples used to build the phylogeny shown in Figure 1B.

Author Contributions: Conceived of or designed study: J.E.T., N.T.M.; performed research: J.E.T., P.K.; analyzed data: J.E.T., P.K., N.T.M.; wrote the paper: J.E.T., P.K., N.T.M. All authors have read and agreed to the published version of the manuscript.

Funding: This research was funded by the National Institute of General Medical Sciences of the National Institutes of Health under award number R35GM133760.

Institutional Review Board Statement: Not applicable.

Informed Consent Statement: Not applicable.

Data Availability Statement: The data presented in this study are available on request from the corresponding author. 
Acknowledgments: The authors would like to thank Robert Schulz for providing the msn-mCherry line. We would also like to thank three anonymous reviewers for their comments to improve our manuscript and the members of the Mortimer Cellular Immunology lab for their input throughout the project. Stocks obtained from the Bloomington Drosophila Stock Center (NIH P40OD018537) were used in this study.

Conflicts of Interest: The authors declare no conflict of interest. The funders had no role in the design of the study; in the collection, analyses, or interpretation of data; in the writing of the manuscript; or in the decision to publish the results.

\section{References}

1. Fleury, F.; Gibert, P.; Ris, N.; Allemand, R. Ecology and life history evolution of frugivorous Drosophila parasitoids. Adv. Parasitol. 2009, 70, 3-44. [CrossRef] [PubMed]

2. Kraaijeveld, A.R.; Godfray, H.C.J. Evolution of host resistance and parasitoid counter-resistance. In Advances in Parasitology; Academic Press: Cambridge, MA, USA, 2009; Volume 70, pp. 257-280.

3. Mortimer, N.T. Parasitoid wasp virulence: A window into fly immunity. Fly 2013, 7, 242-248. [CrossRef] [PubMed]

4. Kim-Jo, C.; Gatti, J.-L.; Poirié, M. Drosophila cellular immunity against parasitoid wasps: A complex and time-dependent process. Front. Physiol. 2019, 10, 603. [CrossRef] [PubMed]

5. Salt, G. The defence reactions of insects to metazoan parasites. Parasitology 1963, 53, 527-642. [CrossRef] [PubMed]

6. Ratner, S.; Vinson, S.B. Phagocytosis and encapsulation: Cellular immune responses in arthropoda. Integr. Comp. Biol. 1983, 23, 185-194. [CrossRef]

7. Strand, M.R.; Pech, L.L. Immunological basis for compatibility in parasitoid-host relationships. Annu. Rev. Entomol. 1995, 40, 31-56. [CrossRef] [PubMed]

8. Vazquez, L.; Alpuche, J.; Maldonado, G.; Agundis, C.; Pereyra-Morales, A.; Zenteno, E. Review: Immunity mechanisms in crustaceans. Innate Immun. 2009, 15, 179-188. [CrossRef]

9. Hillyer, J.F. Insect immunology and hematopoiesis. Dev. Comp. Immunol. 2016, 58, 102-118. [CrossRef]

10. Gorman, M.J.; Severson, D.W.; Cornel, A.J.; Collins, F.H.; Paskewitz, S.M. Mapping a quantitative trait locus involved in melanotic encapsulation of foreign bodies in the malaria vector, Anopheles gambiae. Genetics 1997, 146, 965-971.

11. Zheng, L. Genetic basis of encapsulation response in Anopheles gambiae. Parassitologia 1999, 41, 181-184.

12. Molina-Cruz, A.; DeJong, R.J.; Ortega, C.; Haile, A.; Abban, E.; Rodrigues, J.; Jaramillo-Gutierrez, G.; Barillas-Mury, C. Some strains of Plasmodium falciparum, a human malaria parasite, evade the complement-like system of Anopheles gambiae mosquitoes. Proc. Natl. Acad. Sci. USA 2012, 109, E1957-E1962. [CrossRef] [PubMed]

13. Honti, V.; Csordás, G.; Kurucz, É.; Márkus, R.; Andó, I. The cell-mediated immunity of Drosophila melanogaster: Hemocyte lineages, immune compartments, microanatomy and regulation. Dev. Comp. Immun. 2014, 42, 47-56. [CrossRef]

14. Mortimer, N.T.; Goecks, J.; Kacsoh, B.Z.; Mobley, J.A.; Bowersock, G.J.; Taylor, J.; Schlenke, T.A. Parasitoid wasp venom SERCA regulates Drosophila calcium levels and inhibits cellular immunity. Proc. Natl. Acad. Sci. USA 2013, 110, 9427-9432. [CrossRef] [PubMed]

15. Russo, J.; Dupas, S.; Frey, F.; Carton, Y.; Brehelin, M. Insect immunity: Early events in the encapsulation process of parasitoid (Leptopilina boulardi) eggs in resistant and susceptible strains of Drosophila. Parasitology 1996, 112, 135-142. [CrossRef] [PubMed]

16. Lanot, R.; Zachary, D.; Holder, F.; Meister, M. Postembryonic hematopoiesis in Drosophila. Dev. Biol. 2001, 230, 243-257. [CrossRef]

17. Rizki, T.M.; Rizki, R.M. Lamellocyte differentiation in Drosophila larvae parasitized by Leptopilina. Dev. Comp. Immunol. 1992, 16, 103-110. [CrossRef]

18. Mortimer, N.T.; Kacsoh, B.Z.; Keebaugh, E.S.; Schlenke, T.A. Mgat1-dependent N-glycosylation of membrane components primes Drosophila melanogaster blood cells for the cellular encapsulation response. PLoS Pathog. 2012, 8, e1002819. [CrossRef]

19. Krzemien, J.; Oyallon, J.; Crozatier, M.; Vincent, A. Hematopoietic progenitors and hemocyte lineages in the Drosophila lymph gland. Dev. Biol. 2010, 346, 310-319. [CrossRef]

20. Honti, V.; Csordás, G.; Márkus, R.; Kurucz, E.; Jankovics, F.; Andó, I. Cell lineage tracing reveals the plasticity of the hemocyte lineages and of the hematopoietic compartments in Drosophila melanogaster. Mol. Immunol. 2010, 47, 1997-2004. [CrossRef]

21. Márkus, R.; Laurinyecz, B.; Kurucz, E.; Honti, V.; Bajusz, I.; Sipos, B.; Somogyi, K.; Kronhamn, J.; Hultmark, D.; Andó, I. Sessile hemocytes as a hematopoietic compartment in Drosophila melanogaster. Proc. Natl. Acad. Sci. USA 2009, 106, 4805-4809. [CrossRef]

22. Gerritsma, S.; de Haan, A.; van de Zande, L.; Wertheim, B. Natural variation in differentiated hemocytes is related to parasitoid resistance in Drosophila melanogaster. J. Insect Physiol. 2013, 59, 148-158. [CrossRef] [PubMed]

23. Eslin, P.; Prévost, G. Variation in Drosophila concentration of haemocytes associated with different ability to encapsulate Asobara tabida larval parasitoid. J. Insect Physiol. 1996, 42, 549-555. [CrossRef]

24. Prévost, G.; Eslin, P. Hemocyte load and immune resistance to Asobara tabida are correlated in species of the Drosophila melanogaster subgroup. J. Insect Physiol. 1998, 44, 807-816. [CrossRef] [PubMed]

25. Kraaijeveld, A.R.; Limentani, E.C.; Godfray, H.C. Basis of the trade-off between parasitoid resistance and larval competitive ability in Drosophila melanogaster. Proc. Biol. Sci. 2001, 268, 259-261. [CrossRef] 
26. Kacsoh, B.Z.; Schlenke, T.A. High hemocyte load is associated with increased resistance against parasitoids in Drosophila suzukii, a relative of D. melanogaster. PLoS ONE 2012, 7, e34721. [CrossRef]

27. Sorrentino, R.P.; Melk, J.P.; Govind, S. Genetic analysis of contributions of Dorsal group and JAK-Stat92E pathway genes to larval hemocyte concentration and the egg encapsulation response in Drosoph. Genetics 2004, 166, 1343-1356. [CrossRef]

28. Rizki, R.M.; Rizki, T.M. Parasitoid virus-like particles destroy Drosophila cellular immunity. Proc. Natl. Acad. Sci. USA 1990, 87, 8388-8392. [CrossRef]

29. Chiu, H.; Govind, S. Natural infection of D. melanogaster by virulent parasitic wasps induces apoptotic depletion of hematopoietic precursors. Cell Death Differ. 2002, 9, 1379-1381. [CrossRef]

30. Moreau, S.J.M.; Eslin, P.; Giordanengo, P.; Doury, G. Comparative study of the strategies evolved by two parasitoids of the genus Asobara to avoid the immune response of the host, Drosophila melanogaster. Dev. Comp. Immunol. 2003, 27, 273-282. [CrossRef]

31. Labrosse, C.; Eslin, P.; Doury, G.; Drezen, J.M.; Poirié, M. Haemocyte changes in D. melanogaster in response to long gland components of the parasitoid wasp Leptopilina boulardi: A Rho-GAP protein as an important factor. J. Insect Physiol. 2005, 51, 161-170. [CrossRef]

32. Furihata, S.X.; Matsumoto, H.; Kimura, M.T.; Hayakawa, Y. Venom components of Asobara japonica impair cellular immune responses of host Drosophila melanogaster. Arch. Insect Biochem. Physiol. 2013, 83, 86-100. [CrossRef]

33. Colinet, D.; Dubuffet, A.; Cazes, D.; Moreau, S.; Drezen, J.-M.; Poirié, M. A serpin from the parasitoid wasp Leptopilina boulardi targets the Drosophila phenoloxidase cascade. Dev. Comp. Immunol. 2009, 33, 681-689. [CrossRef]

34. Colinet, D.; Schmitz, A.; Depoix, D.; Crochard, D.; Poirié, M. Convergent use of RhoGAP toxins by eukaryotic parasites and bacterial pathogens. PLoS Pathog. 2007, 3, e203. [CrossRef]

35. Rizki, R.M.; Rizki, T.M. Effects of lamellolysin from a parasitoid wasp on Drosophila blood cells in vitro. J. Exp. Zool. 1991, 257, 236-244. [CrossRef] [PubMed]

36. Eslin, P.; Prévost, G. Racing against host's immunity defenses: A likely strategy for passive evasion of encapsulation in Asobara tabida parasitoids. J. Insect Physiol. 2000, 46, 1161-1167. [CrossRef]

37. Rizki, T.M.; Rizki, R.M.; Carton, Y. Leptopilina heterotoma and L. boulardi: Strategies to avoid cellular defense responses of Drosophila melanogaster. Exp. Parasitol. 1990, 70, 466-475. [CrossRef]

38. Schlenke, T.A.; Morales, J.; Govind, S.; Clark, A.G. Contrasting infection strategies in generalist and specialist wasp parasitoids of Drosophila melanogaster. PLOS Pathog. 2007,3, e158. [CrossRef] [PubMed]

39. Van Alphen, J.J.M.; Nell, H.W. Superparasitism and host discrimination by Asobara tabida Nees (Braconidae: Alysiinae); a larval parasitoid of Drosophilidae. Neth. J. Zool. 1982, 32, 232-260. [CrossRef]

40. Mollema, C. Genetical Aspects of Resistance in a Host-Parasitoid Interaction. Ph.D. Thesis, University of Leiden, Leiden, The Netherlands, 1988.

41. Salt, G. Experimental studies in insect parasitism. II.-Superparasitism. Proc. Biol. Sci. 1934, 114, 455-476. [CrossRef]

42. Luna, M.G.; Desneux, N.; Schneider, M.I. Encapsulation and self-superparasitism of Pseudapanteles dignus (Muesebeck) (Hymenoptera: Braconidae), a parasitoid of Tuta absoluta (Meyrick) (Lepidoptera: Gelechiidae). PLoS ONE 2016, 11, e0163196. [CrossRef]

43. Van Alphen, J.J.; Visser, M.E. Superparasitism as an adaptive strategy for insect parasitoids. Annu. Rev. Entomol. 1990, 35, 59-79. [CrossRef] [PubMed]

44. Ashfaq, M.; Sabir, J.S.M.; El-Ansary, H.O.; Perez, K.; Levesque-Beaudin, V.; Khan, A.M.; Rasool, A.; Gallant, C.; Addesi, J.; Hebert, P.D.N. Insect diversity in the Saharo-Arabian region: Revealing a little-studied fauna by DNA barcoding. PLoS ONE 2018, 13, e0199965. [CrossRef] [PubMed]

45. Smith, M.A.; Eveleigh, E.S.; McCann, K.S.; Merilo, M.T.; McCarthy, P.C.; Van Rooyen, K.I. Barcoding a quantified food web: Crypsis, concepts, ecology and hypotheses. PLoS ONE 2011, 6, e14424. [CrossRef] [PubMed]

46. Hebert, P.D.N.; Ratnasingham, S.; Zakharov, E.V.; Telfer, A.C.; Levesque-Beaudin, V.; Milton, M.A.; Pedersen, S.; Jannetta, P.; de Waard, J.R. Counting animal species with DNA barcodes: Canadian insects. Philos. Trans. R. Soc. Lond. B Biol. Sci. 2016, 371, 20150333. [CrossRef] [PubMed]

47. Guerrieri, E.; Giorgini, M.; Cascone, P.; Carpenito, S.; van Achterberg, C. Species diversity in the parasitoid genus Asobara (Hymenoptera: Braconidae) from the native area of the fruit fly pest Drosophila suzukii (Diptera: Drosophilidae). PLoS ONE 2016, 11, e0147382. [CrossRef]

48. Vet, L.E.M.; Janse, C.J. Fitness of two sibling species of Asobara (Braconidae: Alysiinae), larval parasitoids of Drosophilidae in different microhabitats. Ecol. Entomol. 1984, 9, 345-354. [CrossRef]

49. Anderl, I.; Vesala, L.; Ihalainen, T.O.; Vanha-aho, L.-M.; Andó, I.; Rämet, M.; Hultmark, D. Transdifferentiation and proliferation in two distinct hemocyte lineages in Drosophila melanogaster larvae after wasp infection. PLoS Pathog. 2016, 12, e1005746. [CrossRef]

50. Rizki, M.T.M. Alterations in the haemocyte population of Drosophila melanogaster. J. Morphol. 1957, 100, 437-458. [CrossRef]

51. Tokusumi, T.; Sorrentino, R.P.; Russell, M.; Ferrarese, R.; Govind, S.; Schulz, R.A. Characterization of a lamellocyte transcriptional enhancer located within the misshapen gene of Drosophila melanogaster. PLoS ONE 2009, 4, e6429. [CrossRef]

52. Avet-Rochex, A.; Boyer, K.; Polesello, C.; Gobert, V.; Osman, D.; Roch, F.; Augé, B.; Zanet, J.; Haenlin, M.; Waltzer, L. An in vivo RNA interference screen identifies gene networks controlling Drosophila melanogaster blood cell homeostasis. BMC Dev. Biol. 2010, 10, 65. [CrossRef] 
53. Yang, H.; Kronhamn, J.; Ekström, J.-O.; Korkut, G.G.; Hultmark, D. JAK/STAT signaling in Drosophila muscles controls the cellular immune response against parasitoid infection. EMBO Rep. 2015, 16, 1664-1672. [CrossRef] [PubMed]

54. Sorrentino, R.P.; Carton, Y.; Govind, S. Cellular immune response to parasite infection in the Drosophila lymph gland is developmentally regulated. Dev. Biol. 2002, 243, 65-80. [CrossRef] [PubMed]

55. Su, Y.C.; Treisman, J.E.; Skolnik, E.Y. The Drosophila Ste20-related kinase misshapen is required for embryonic dorsal closure and acts through a JNK MAPK module on an evolutionarily conserved signaling pathway. Genes Dev. 1998, 12, 2371-2380. [CrossRef] [PubMed]

56. Delaney, J.R.; Stöven, S.; Uvell, H.; Anderson, K.V.; Engström, Y.; Mlodzik, M. Cooperative control of Drosophila immune responses by the JNK and NF-KB signaling pathways. EMBO J. 2006, 25, 3068-3077. [CrossRef] [PubMed]

57. Arthur, J.S.C.; Ley, S.C. Mitogen-Activated protein kinases in innate immunity. Nat. Rev. Immunol. 2013, 13, 679-692. [CrossRef]

58. Williams, M.J.; Wiklund, M.-L.; Wikman, S.; Hultmark, D. Rac1 signalling in the Drosophila larval cellular immune response. J. Cell Sci. 2006, 119, 2015-2024. [CrossRef]

59. Wertheim, B.; Kraaijeveld, A.R.; Hopkins, M.G.; Boer, M.W.; Godfray, H.C.J. Functional genomics of the evolution of increased resistance to parasitism in Drosoph. Mol. Ecol. 2011, 20, 932-949. [CrossRef] [PubMed]

60. Jones, R.M.; Wu, H.; Wentworth, C.; Luo, L.; Collier-Hyams, L.; Neish, A.S. Salmonella AvrA coordinates suppression of host immune and apoptotic defenses via JNK pathway blockade. Cell Host Microbe 2008, 3, 233-244. [CrossRef]

61. Chen, H.; Yang, D.; Han, F.; Tan, J.; Zhang, L.; Xiao, J.; Zhang, Y.; Liu, Q. The bacterial T6SS effector EvpP prevents NLRP3 inflammasome activation by inhibiting the Ca2+-dependent MAPK-Jnk pathway. Cell Host Microbe 2017, 21, 47-58. [CrossRef]

62. Haidar, M.; Rchiad, Z.; Ansari, H.R.; Ben-Rached, F.; Tajeri, S.; Latre De Late, P.; Langsley, G.; Pain, A. miR-126-5p by direct targeting of JNK-interacting protein-2 (JIP-2) plays a key role in Theileria-infected macrophage virulence. PLoS Pathog. 2018, 14, e1006942. [CrossRef]

63. Cattenoz, P.B.; Sakr, R.; Pavlidaki, A.; Delaporte, C.; Riba, A.; Molina, N.; Hariharan, N.; Mukherjee, T.; Giangrande, A. Temporal specificity and heterogeneity of Drosophila immune cells. EMBO J. 2020, 39, e104486. [CrossRef]

64. Cho, B.; Yoon, S.-H.; Lee, D.; Koranteng, F.; Tattikota, S.G.; Cha, N.; Shin, M.; Do, H.; Hu, Y.; Oh, S.Y.; et al. Single-Cell transcriptome maps of myeloid blood cell lineages in Drosophila. Nat. Commun. 2020, 11, 4483. [CrossRef] [PubMed]

65. Fu, Y.; Huang, X.; Zhang, P.; van de Leemput, J.; Han, Z. Single-Cell RNA sequencing identifies novel cell types in Drosophila blood. J. Genet. Genom. 2020, 47, 175-186. [CrossRef]

66. Tattikota, S.G.; Cho, B.; Liu, Y.; Hu, Y.; Barrera, V.; Steinbaugh, M.J.; Yoon, S.-H.; Comjean, A.; Li, F.; Dervis, F.; et al. A single-cell survey of Drosophila blood. eLife 2020, 9, e54818. [CrossRef]

67. Fisher, R.C. A study in insect multiparasitism. I. Host selection and oviposition. J. Exp. Biol. 1961, 38, $267-275$.

68. Salt, G. Competition among insect parasitoids. Mechanisms in biological competition. Symp. Soc. Exp. Biol. 1961, 15, 96-119.

69. Varaldi, J.; Fouillet, P.; Ravallec, M.; López-Ferber, M.; Boulétreau, M.; Fleury, F. Infectious behavior in a parasitoid. Science 2003, 302, 1930. [CrossRef] [PubMed]

70. Varaldi, J.; Boulétreau, M.; Fleury, F. Cost induced by viral particles manipulating superparasitism behaviour in the parasitoid Leptopilina boulardi. Parasitology 2005, 131, 161-168. [CrossRef] [PubMed]

71. Varaldi, J.; Petit, S.; Boulétreau, M.; Fleury, F. The virus infecting the parasitoid Leptopilina boulardi exerts a specific action on superparasitism behaviour. Parasitology 2006, 132, 747-756. [CrossRef]

72. Chui, H.; Sorrentino, R.P.; Govind, S. Suppression of the Drosophila cellular immune response by Ganaspis xanthopoda. In Phylogenetic Perspectives on the Vertebrate Immune System; Beck, G., Sugumaran, M., Cooper, E.L., Eds.; Advances in Experimental Medicine and Biology-Springer US: New York, NY, USA, 2001; pp. 161-167. ISBN 978-1-4613-5481-9.

73. Labrosse, C.; Stasiak, K.; Lesobre, J.; Grangeia, A.; Huguet, E.; Drezen, J.M.; Poirie, M. A RhoGAP protein as a main immune suppressive factor in the Leptopilina boulardi (Hymenoptera, Figitidae)—Drosophila melanogaster interaction. Insect Biochem. Mol. Biol. 2005, 35, 93-103. [CrossRef]

74. Morales, J.; Chiu, H.; Oo, T.; Plaza, R.; Hoskins, S.; Govind, S. Biogenesis, structure, and immune-suppressive effects of virus-like particles of a Drosophila parasitoid, Leptopilina victoriae. J. Insect Physiol. 2005, 51, 181-195. [CrossRef] [PubMed]

75. Moreau, S.J.M.; Asgari, S. Venom proteins from parasitoid wasps and their biological functions. Toxins 2015, 7, 2385-2412. [CrossRef] [PubMed]

76. Coulette, Q.; Lemauf, S.; Colinet, D.; Prévost, G.; Anselme, C.; Poirié, M.; Gatti, J.-L. Biochemical characterization and comparison of aspartylglucosaminidases secreted in venom of the parasitoid wasps Asobara tabida and Leptopilina heterotoma. PLoS ONE 2017, 12, e0181940. [CrossRef]

77. Moreau, S.J.M.; Dingremont, A.; Doury, G.; Giordanengo, P. Effects of parasitism by Asobara tabida (Hymenoptera: Braconidae) on the development, survival and activity of Drosophila melanogaster larvae. J. Insect Physiol. 2002, 48, 337-347. [CrossRef]

78. Moreau, S.J.; Doury, G.; Giordanengo, P. Intraspecific variation in the effects of parasitism by Asobara tabida on phenoloxidase activity of Drosophila melanogaster larvae. J. Invertebr. Pathol. 2000, 76, 151-153. [CrossRef] [PubMed]

79. Moreau, S.J.M.; Vinchon, S.; Cherqui, A.; Prévost, G. Components of Asobara venoms and their effects on hosts. Adv. Parasitol. 2009, 70, 217-232. [CrossRef]

80. Goecks, J.; Mortimer, N.T.; Mobley, J.A.; Bowersock, G.J.; Taylor, J.; Schlenke, T.A. Integrative approach reveals composition of endoparasitoid wasp venoms. PLoS ONE 2013, 8, e64125. [CrossRef] 
81. Cavigliasso, F.; Mathé-Hubert, H.; Kremmer, L.; Rebuf, C.; Gatti, J.-L.; Malausa, T.; Colinet, D.; Poirié, M. Rapid and differential evolution of the venom composition of a parasitoid wasp depending on the host strain. Toxins 2019, 11, 629. [CrossRef]

82. Dubuffet, A.; Colinet, D.; Anselme, C.; Dupas, S.; Carton, Y.; Poirié, M. Variation of Leptopilina boulardi success in Drosophila hosts: What is inside the black box? In Advances in Parasitology; Academic Press: Cambridge, MA, USA, 2009; Volume 70, pp. 147-188.

83. Mathé-Hubert, H.; Kremmer, L.; Colinet, D.; Gatti, J.-L.; Van Baaren, J.; Delava, É.; Poirié, M. Variation in the venom of parasitic wasps, drift, or selection? Insights From a multivariate QST analysis. Front. Ecol. Evol. 2019, 7, 156. [CrossRef]

84. Folmer, O.; Black, M.; Hoeh, W.; Lutz, R.; Vrijenhoek, R. DNA primers for amplification of mitochondrial cytochrome c oxidase subunit I from diverse metazoan invertebrates. Mol. Mar. Biol. Biotechnol. 1994, 3, 294-299.

85. Altschul, S.F.; Gish, W.; Miller, W.; Myers, E.W.; Lipman, D.J. Basic Local Alignment Search Tool. J. Mol. Biol. 1990, 215, 403-410. [CrossRef]

86. Camacho, C.; Coulouris, G.; Avagyan, V.; Ma, N.; Papadopoulos, J.; Bealer, K.; Madden, T.L. BLAST+: Architecture and applications. BMC Bioinform. 2009, 10, 421. [CrossRef] [PubMed]

87. Kumar, S.; Stecher, G.; Li, M.; Knyaz, C.; Tamura, K. MEGA X: Molecular evolutionary genetics analysis across computing platforms. Mol. Biol. Evol. 2018, 35, 1547-1549. [CrossRef] [PubMed]

88. Stecher, G.; Tamura, K.; Kumar, S. Molecular Evolutionary Genetics Analysis (MEGA) for macOS. Mol. Biol. Evol. 2020, 37, 1237-1239. [CrossRef] [PubMed]

89. Nomano, F.Y.; Mitsui, H.; Kimura, M.T. Capacity of Japanese Asobara species (Hymenoptera; Braconidae) to parasitize a fruit pest Drosophila suzukii (Diptera; Drosophilidae). J. Appl. Entomol. 2015, 139, 105-113. [CrossRef]

90. Murata, Y.; Ideo, S.; Watada, M.; Mitsui, H.; Kimura, M.T. Genetic and physiological variation among sexual and parthenogenetic populations of Asobara japonica (Hymenoptera: Braconidae), a larval parasitoid of drosophilid flies. Eur. J. Entomol. 2013, 106, 171-178. [CrossRef]

91. Kimura, M. A simple method for estimating evolutionary rates of base substitutions through comparative studies of nucleotide sequences. J. Mol. Evol. 1980, 16, 111-120. [CrossRef]

92. R Foundation for Statistical Computing. R Core Team R: A Language and Environment for Statistical Computing; R Foundation for Statistical Computing: Vienna, Austria, 2020.

93. Hothorn, T.; Bretz, F.; Westfall, P. Simultaneous inference in general parametric models. Biom. J. 2008, 50, 346-363. [CrossRef]

94. Bates, D.; Mächler, M.; Bolker, B.; Walker, S. Fitting linear mixed-effects models using lme4. J. Stat. Softw. 2015, 67, 1-48. [CrossRef]

95. Kuznetsova, A.; Brockhoff, P.B.; Christensen, R.H.B. lmerTest package: Tests in linear mixed effects models. J. Stat. Softw. 2017, 82, 1-26. [CrossRef]

96. Wickham, H. The split-apply-combine strategy for data analysis. J. Stat. Softw. 2011, 40, 1-29. [CrossRef]

97. Lê, S.; Josse, J.; Husson, F. FactoMineR: An R package for multivariate analysis. J. Stat. Softw. 2008, 25, 1-18. [CrossRef]

98. Kassambara, A.; Mundt, F. Factoextra: Extract and Visualize the Results of Multivariate Data Analyses. Available online: https: / /CRAN.R-project.org/package=factoextra (accessed on 17 July 2020).

99. Wickham, H. ggplot2: Elegant Graphics for Data Analysis; Springer: New York, NY, USA, 2009; ISBN 978-0-387-98141-3. 